\title{
VERIFICATION OF THE TRACEABILITY MODEL OF AUTOCHTHONOUS POULTRY BREEDS
}

\author{
Lukáš Jurčaga $^{1 \bowtie}$, Radoslav Židek², Jozef Golian², Lubomír Belej², Alžbeta Demianová2, \\ Marek Bobko', Alica Bobková ${ }^{2}$ \\ ${ }^{I}$ Department of Technology and Quality of Animal Products, Slovak University of Agriculture in Nitra, Tr. \\ A. Hlinku 2, 94976 Nitra, Slovak Republic \\ ${ }^{2}$ Department of Food Hygiene and Safety, Slovak University of Agriculture in Nitra, Tr. A. Hlinku 2, 94976 \\ Nitra, Slovak Republic \\ $\triangle_{x j u r c a g a @ u n i a g . s k}$ \\ https://doi.org/10.34302/crpjfst/2020.12.4.6 \\ Article history: \\ Received: \\ 17 May 2020 \\ Accepted: \\ 1 December 2020 \\ Keywords: \\ Chicken; \\ Microsatellite; \\ Traceability; \\ F1 generation.

\section{ABSTRACT} \\ Microsatellite markers are reliable and cheap method for studying diversity \\ among animal breeds. They are widely used for separation of related animal \\ breeds on genetic level. When used in food industry, they have great \\ potential to be used for authentication of animal food products. We are \\ aiming to explore the variability of alleles in selected markers in modeled \\ F1 generation of Slovak breeds of chicken. We want to compare, if \\ previously proposed traceability model is relevant for next generation of \\ chickens or it is limited to one, parental, generation. Our analysis was based \\ on 7 selected microsatellite markers. We modeled genotypes of $42 \mathrm{~F} 1$ \\ generation individuals of Oravka tawny and 42 of Oravka white, derived \\ from 1 rooster and 7 chickens from each breed. In our study, we used PCoA \\ analysis and neighbor joining (NJ) analysis. With usage of both analyzes, \\ we proved, that both generations are unique and genetic distance between \\ individuals of different color breed are wide enough. We proved, that we \\ only need to genotype the parental generation of both Oravka chicken tawny \\ and white breeds. After creating F1 generation, we are reliably able to \\ separate those populations. There is no need to genotype whole F1 \\ generation. This provide huge financial benefits. Furthermore, we are able \\ to trace and authenticate whole $\mathrm{F} 1$ production generation.
}

\section{Introduction}

Providing the food and economic income, production of poultry serves an important role, especially for small scale farmers. Despite the importance of local breeds of poultry, their populations have been decreasing in recent years. Some breeds are even becoming endangered and threated by extinction. This is because of low performance of local chickens compared to highly specialized lines that have high performance, mixed rearing with other breeds, and lack of suitable conservation strategies to protect local chickens. Decreasing numbers of local chicken may be connected to the loss of valuable genetic variability and unique traits and characteristics. The convention on biological diversity has put the need to conserve farm animal genetic diversity on the agenda. Regarding to the farm animal diversity conservation, a unified approach accounting for two main roads to conservation has been established. This includes the prevention of breed extinction, and management of within breed genetic variability with the main objective of controlling genetic drift (Simianer, 2005). In 
last few years, the goal of preserving genetic diversity has become more and more important. The very beginning of the commercial breeding of various poultry species took place since the middle of 20th century. Since that, industrial breeding of chicken was based on rather small circle of highly specialized lines, which originated from small number of world's most common specialized breeds. Due to this, large number of combined breeds of chickens are on the brink of extinction by long-term breeding. This is indicated by the data on the increasing rates of exhaustion of the gene pool as a result of the crowding out local breeds by transnational commercial breeds (Abdelaziz et al., 2019). Since the start of commercial poultry breeding, chicken genetic diversity has become partitioned among relatively few highly specialized lines. As a result of this, many dualpurpose breeds, originated from centuries-long domestication and breeding, are now in the danger of perishing. However, these older breeds pose a resource of genes valuable for the future breeding activities and research purposes. Therefore, it is necessary to assess the diversity at the molecular level, in a wide range of chicken populations, including commercial lines, traditional breeds, experimental lines, and the red jungle fowl, in order to provide recommendations regarding to the future management or conservation of chicken biodiversity. Even though the decision on conservation of population 's gene pool must be based on various sources of information, including specific traits interesting for breeding, molecular markers has a potential to be helpful and important initial guide (Hillel et al., 2003). Biodiversity conservation is a topic of interest and domestic animal diversity is an esential component (FAO, 2011). Although scientists are focused on genetic resources of all farm animals, the conservation of poultry has attracted increasing attention for years now (Tadano et al., 2013). In comparison to fastgrowing broilers, older, native chicken breeds and their hybrids have lower gain of weight, smaller proportions of breast muscle in the carcass. However, their meat has many quality characteristics, which are highly valued by modern day consumers (Sokołowicz et al., 2016). Oravka is a dual-purpose breed of chicken, originated from Slovakia region of Orava. Oravka was bred with the purpose of being able to adapt to harsh conditions of their native environment. This breed is also the only one with the status of native chicken in Slovakia. Development of Oravka chicken started in 1950s under the guidance of the Research Institute for Poultry. First stage was a combinatorial crossing of regional breeds with breeds of Rhode Island Red, New Hampshire and Wyandotte White (Chmelničná, 2004). The goal was to develop a breed, which can be kept in free range, and be suitable for harsh climatic conditions of northern Slovakia. It was adapted for egg and meat production. In 1990 was recognized as an independent breed (Hanusová et al., 2017). In the animal production sector, microsatellite markers have been used for longer than a decade for characterization and conservation of livestock biodiversity, as well as for traceability of food products. Genotyping standards are currently used for livestock animals. Those are standardized SNP panels, which allows the characterization of tens, even hundreds of thousand markers per sample. Microsatellite markers still represents a useful tool used for characterization of animal breeds mostly because of their low cost and easy implementation of genotyping protocols. FAO published recommendations for standardized sets of microsatellite loci to be used for studying diversity in major livestock species in order to make possible the comparison of results across different research projects (Abdurakhmonov, 2016). When it comes to individual identification and parentage assessment, genetic markers are important resources. Short tandem repeats (STRs) have been the traditional DNA markers of choice in many species. However, advantages in technologies show that nucleotide polymorphisms (SNPs) are becoming an attractive alternative, especially in recent years. SNPs can be highly multiplexed and automatically scored, which allows an easier standardization and sharing among different 
laboratories. The domestic horse currently uses STR based DNA typing. (Seo et al., 2013). Microsatellite markers have many applications in molecular studies. They are proven to be most accurate and efficient tools for studying genetic diversities and relationships (Dávila et al., 2009) connections among populations and genetic fitness of whole populations, including paternity determination (Witzenberger and Hochkirch, 2011). Since the PCR technologies became commonly available, it has been easy to amplify DNA isolated from both plants and animals. Microsatellite has short repeat units and it is a good example of nuclear DNA markers (Rosenbom et al., 2015) that has found its wide application in molecular studies. Comparing to other markers, the greatest advantages of

microsatellite markers are their high variability and distribution (Yilmaz et al., 2015). Extent of diversity in livestock populations across the globe has been gained through the usage of microsatellite markers (Granevitze et al., 2007). Given the fact that they can easily show the information essential for creating long term breeding plans, designing of breeding programs planning conservation strategies, traceability and in parentage verifications. In recent years, selection of microsatellite markers has been based on single criterion called polymorphism information content. For determination of this parameter, researchers have been using the formula suggested by

With the proof that we are able to separate populations of Oravka tawny and white, it is expected that we will be able to do so even with F1 generations of observed and genotyped chickens. Despite being genetically closest,
Oravka tawny and white could be separated. With low variability in selected markers within one population, there is a low chance for the first generation of selected chickens to close the genetic distance between them.

Botstein et al. (1980) and when PIC value of a marker equals the threshold value of 0.50 or above, such marker is called to be informative (Olowofeso et al., 2016).

\section{Materials and methods}

For the research, we used genotyped individuals from work of Belej et al., (2019). We randomly selected one rooster and 7 hens of Oravka tawny (Table 1.) to simulate the breeding conditions in farm breeding process. We modeled 6 offspring from the rooster and each hen for total $42 \mathrm{~F} 1$ generation individuals. The same process was used with Oravka white population. The final step was comparing those populations to visualize genetic distance between F1 populations and parent individuals.

\subsection{Statistical analysis}

To create a random combination of alleles of modeled offsprings Microsoft Excel was used. To calculate the genetic distance between observed individuals, we used Microsoft Excel add-on program GenAlEx 6.5. Principal coordinates analysis (PCoA) was executed in GenAlEx 6.5 as well.

RStudio 3.6.0 ("Planting of a Tree") with additional adegenet and ape libraries software was used to perform and visualize the neighbor joining $(\mathrm{NJ})$.

Table 1. Genotypes of parental generation

\begin{tabular}{|c|c|c|c|c|c|c|c|c|c|c|c|c|c|c|}
\hline \multirow{2}{*}{\multicolumn{3}{|c|}{\begin{tabular}{|l|l|} 
Sample & LEI02 \\
Oravka tawny \\
\end{tabular}}} & \multicolumn{2}{|c|}{ MCW0034 } & \multicolumn{2}{|c|}{ LEI0192 } & \multicolumn{2}{|c|}{ LEI0166 } & \multicolumn{2}{|c|}{ MCW0069 } & \multicolumn{2}{|c|}{ LEI0234 } & \multicolumn{2}{|c|}{ LEI0228 } \\
\hline & & & & & & & & & & & & & & \\
\hline PAR1 & 86 & 86 & & & 289 & 3 & 8 & 8 & 5 & & 292 & 2 & 162 & 174 \\
\hline PAR2 & 86 & 86 & 21 & 221 & 253 & 289 & 348 & 348 & 155 & 155 & 288 & 288 & 162 & 224 \\
\hline PAR3 & 86 & 8 & 221 & 221 & 269 & 293 & 348 & 348 & 155 & 163 & 288 & 292 & 162 & 162 \\
\hline PAR4 & 86 & 86 & 221 & 221 & 289 & 293 & 348 & 348 & 159 & 161 & 292 & 308 & 232 & 232 \\
\hline PAR5 & 90 & 90 & 221 & 233 & 269 & 297 & 348 & 348 & 161 & 165 & 292 & 292 & 162 & 174 \\
\hline PAR6 & 86 & 86 & 219 & 221 & 269 & 289 & 348 & 348 & 159 & 161 & 288 & 296 & 228 & 228 \\
\hline
\end{tabular}




\begin{tabular}{|l|l|l|l|l|l|l|l|l|l|l|l|l|l|l|}
\hline PAR7 & 86 & 86 & 233 & 233 & 289 & 289 & 348 & 348 & 159 & 163 & 292 & 308 & 164 & 228 \\
\hline PAR8 & 86 & 86 & 221 & 221 & 289 & 293 & 348 & 348 & 159 & 159 & 292 & 308 & 224 & 224 \\
\hline Oravka white \\
\hline WHP1 & 86 & 86 & 223 & 231 & 253 & 253 & 344 & 344 & 159 & 161 & 212 & 304 & 162 & 208 \\
\hline WHP2 & 86 & 86 & 221 & 223 & 253 & 253 & 344 & 352 & 161 & 161 & 212 & 260 & 208 & 208 \\
\hline WHP3 & 86 & 86 & 223 & 231 & 253 & 253 & 344 & 352 & 159 & 163 & 300 & 304 & 162 & 204 \\
\hline WHP4 & 90 & 90 & 229 & 229 & 253 & 253 & 344 & 348 & 155 & 165 & 212 & 212 & 228 & 232 \\
\hline WHP5 & 90 & 90 & 231 & 231 & 253 & 293 & 348 & 352 & 155 & 161 & 212 & 216 & 228 & 232 \\
\hline WHP6 & 86 & 86 & 227 & 229 & 289 & 289 & 348 & 348 & 161 & 161 & 300 & 312 & 162 & 162 \\
\hline WHP7 & 86 & 86 & 229 & 229 & 301 & 301 & 356 & 356 & 161 & 173 & 212 & 212 & 162 & 204 \\
\hline WHP8 & 86 & 86 & 221 & 223 & 253 & 253 & 344 & 352 & 161 & 161 & 212 & 260 & 208 & 208 \\
\hline
\end{tabular}

\section{Results and discussions}

The concept of traceability throughout the food supply chain is recognised within the European Union with the regulation (EC) No. $178 / 2002$, in which traceability is defined as the ability to trace and to follow food, feed and ingredients through all stages of production, processing and distribution. As a consequence, traceability requires systems for animal identification and registration and for labelling animal products, in order to ensure a link between the animal and the meat produced from it (Ammendrup and Fussel, 2001; Caporale et al., 2001).

Microsatellite markers had been widely investigated for many applications such as genetic identification, assessment of parentage, breed assignment tests and traceability (Dalvit et al., 2007; Rosa et al., 2013; Tolone et al., 2012; Sardina et al., 2015). Microsatellite markers have been recommended as the marker of choice for biodiversity studies (FAO, 2011). They are regarded as the most convenient tool for determination of heterozygosity and genetic distances. As they are numerous and randomly distributed throughout the chicken genome, they show a higher degree of polymorphisms, follow codominant inheritance and are ideal for deciphering genetic variability (Zhou et al., 2008; Abebe, et al., 2015). A prerequisite for the development of efficient SNP-based identification systems is the description of a minimal set with sufficient power to uniquely identify individuals and their parents in a variety of popular breeds and crossbred populations
(Heaton et al., 2002), even though the information content in the SNP set may vary significantly between populations (Krawczak, 1999, Fernández et al. 2013).

As mentioned, our analysis was based od 7 microsatellite markers. The variability of alleles within the populations of selected chicken breeds is low. Chickens used in our study were genotyped by authors Belej et al., (2019). Genetic structure of selected chicken individuals is listed in Table 1. First individual in every sample column is a rooster, other 7 are hens. DNA based methods, with the use of microsatellites markers, are powerful tools already fully established in parentage typing, individual assignment (Jobling and Gill, 2004), population genetics (Moioli et al., 2001) and evaluation of genetic resources (Pariset et al., 2003); moreover, microsatellite based tests have been proposed for individual breed identification (Ciampolini et al., 2000). Recently, DNA identification techniques have also been proposed in the field of meat traceability to implement conventional animal identification. (Cunningham and Meghen, 2001; Stanford et al., 2001). These methods foresee that a meat sample, taken at any point in the retail chain, is analyzed by a DNA test, and the obtained fingerprint is compared with the DNA fingerprint of the animal which is thought to have given that meat. The animal DNA profile is obtained from tissue samples collected either from the living animal, or during slaughter, and then stored. 
Principal Coordinates (1 vs 2)

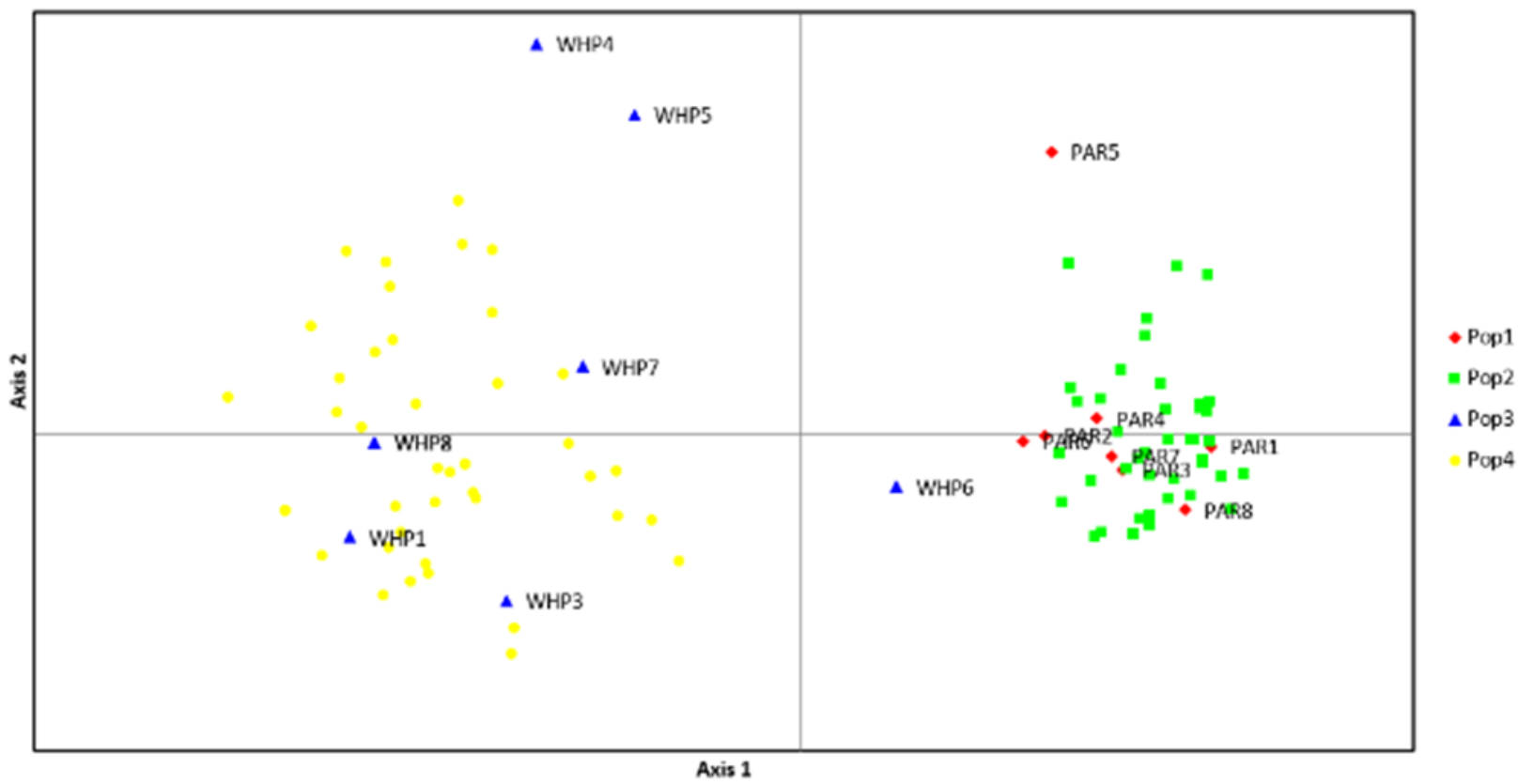

Figure 1. Scatter plot of PCoA analysis

Matching between the alleles of the two samples provide an information whether the declared origin of the meat is correct or not (Orrú et al. 2006). Microsatellites are considered to be the most variable types of DNA sequence in the genome. In contrast to unique DNA, microsatellite polymorphisms derive mainly from variability in length, rather than in the primary sequence. Moreover, genetic variation at many microsatellite loci is characterized by high heterozygosity and the presence of multiple alleles, which is in sharp contrast to unique DNA (Ellegren, 2004). Scatter plot of PCoA analysis shows that both parental generations and F1 generations are clearly separated. Percentage of variation explained by the first 3 axes are for axis $1: 40,38 \%$, for axis $2: 7,57 \%$ and for axis 3 : $6,42 \%$. In the Figure 1 is showing the visualization of PCoA analysis using axis 1 and 2. Together, cumulative percentage of variation explained by the first 2 axes is $47,95 \%$. Parental population of Oravka tawny is shown by red colour and marked as Pop1. It's the F1 population, Pop2 is in green colour. For Oravka white, blue Pop3 shows parental generation and yellow Pop4 modeled F1 generation. It is clearly visible that $\mathrm{F} 1$ generations are separated from each other. It means that not even on the level of the first generation, genetic distance between populations of Oravkas is not closing. The same is true for the ordering of genetic distances among populations assessed for different markers (Jorde et al., 2000). Therefore, it is reasonable to believe that the ordering breeds of diversity, among chicken, and distances seen here for microsatellites in DNA pools, would not be very different with using other genetic marker systems. The microsatellite loci used here were selected to be polymorphic for usage in gene mapping (Belej et al., 2019). Populations which do not fit with an ideal panmictic population are said to be structured (Barker, 1989). This structure is exhibited with a different pattern of frequencies and fixed alleles.

Pure breeds of livestock are the products of thousands of years of selection; they are closed populations and each of them shows a peculiar genetic structure (Orrú et al, 2006).

The algorithm of the neighbor joining (NJ) method is similar to that of the ST method, which objective is to construct the topology of a tree. On the contrary, the NJ method provides 
not only the topology, but also the branch lengths of the final tree. Before discussing the algorithm of the present method, let us first define the term "neighbors." A pair of neighbors is a pair of OTUs connected through a single interior node in an unrooted, bifurcating tree (Saitou and Nei, 1987). As well as scatter plot, neighbor joining method proves, that our investigated F1 populations are segregated on genetic distance. The fan type neighbor-joining is a simple plot that connects the most genetically related individuals. In NJ plot Figure 2 it is visible, that 2 different main branches were created. On those branches are individuals of both Oravkas populations, parental and $\mathrm{F} 1$ generations.



Figure 2. Vizualization of NJ analysis

\section{Conclusions}

We proved that selected microsatellite markers are eligible for authentication of food products of Oravaka tawny even for the F1 generations. This method could be the method of authentication and base line for Oravka products to be recognized as food with protected geographical indication.

The knowledge of genotyped parental generations let us predict and model the whole F1 production generation with all possible combinations of alleles from parental generation. The analysis of principal coordinates and neighbor joining (NJ) is showing, that modeled F1 generations are easily separated. In conclusion that means, we do not need to genotype a whole new generation. This created authentication method will be operational and functional for the F1 generation and products gained from those individuals. There is no need to genotype the F1 generation, because genetic distance is wide enough to reliably differ one population from another.

This bears great financial benefit for the authentication model. The need to observe and genotype only parental generation reduce the cost of microsatellite method. The method of microsatellite markes is proving to be fairly cheap and reliable for food authentication purposes. 


\section{References}

Abdelaziz, N., Marey, N., Duksi, F., Rebouh, N.Y., Boli, B.I., Gadzhikurbanov, A., Gladyr, E.A., Klenovitsky, P.M., Nikishov, A.A., Kulikov, E.V., Vatnikov, Yu.A. (2019) Genetic diversity among local chicken breeds egypt, using microsatellite dna markers. EurAsian Journal of BioSciences. 13(2), 1149-1154.

Abdurakhmonov, I.Y. (2016) Microsatellite Markers (Janeza Trdine 9, 51000 Rijeka, Croatia)

Abebe, A.S., Mikko, S., Johansson, A.M. (2015) Genetic diversity of five local Swedish chicken breeds detected by microsatellite markers, PLoS ONE. 10(4), 1-13.

Ammendrup, S., Fussel, A.E. (2001) Legislative requirements for the identification and traceability of farm animals within the European Union. Revue Scientifique et Technique de $l$ Office International des Epizooties 20(2), 437-444.

Barker, J.S.F. (1989) Population structure In 'Evolution and animal breeding. Reviews on molecular and quantitative approaches in honour of Alan Robertson' (Ed Hill WG, Mackay TFC) pp. 75-80 (Wallingford, UK: C.A.B. International)

Belej, L., Jurčaga, L., Mindek, S.,Hrnčár, C., Capla, J., Zajác, P., Benešová, L., Židek, R., Golian, J. (2019) Authentication of poultry products at the breed level using genetic markers. Potravinarstvo Slovak Journal of Food Sciences 13(1), 956-960.

Botstein, D., White, R., Skolnick, M., Davis, R. W. 1980. Construction of genetic linkage map in man using restriction fragment length polymorphisms. American Journal of Human Genetics 32, 314-331.

Caporale, V., Giovannini, A., Francesco, C., Calistri, P. (2001). Importance of traceability of animals and animal products in epidemiology. Revue Scientifique et Technique de $l$ Office International des Epizooties 20(2), 372-378.

Ciampolini, R., Leveziel, H., Mazzanti, E., Grohs, C., Cianci, D. (2000) Genomic identification of the breed of an individual or its tissue. Meat Science 54(1), 35-40.

Cunningham, E. P. and Meghen, C. M. (2001) Biological identification systems: Genetic markers. OIE Revue Scientifique et Technique 20(2), 491-499.

Dalvit, C., De Marchi, M., Cassandro, M. (2007) Genetic traceability of livestock products: A review. Meat Science 77, 437-449.

Dávila, S.G., Gil, M.G., Resino-Talaván, P., Campo, J.L. (2009) Evaluation of diversity between different Spanish chicken breeds, a tester line, and a White Leghorn population based on microsatellite markers. Poultry Science 88(12), 2518-2525.

Ellegren, H. (2004) Microsatellites: Simple sequences with complex evolution. Nature Reviews Genetics 5(6), 435-445.

FAO (2011) Molecular genetic characterization of animal genetic resources. FAO Animal Production and Health Guidelines. No. 9. Rome

Fernández, M.E., Goszczynski, D.E., Lirón, J.P., Villegas-Castagnasso, E.E., Carino, MH, Ripoli MV, Rogberg-Muñoz A, Posik D.M., Peral-García, P., Giovambattista, G. (2013) Comparison of the effectiveness of microsatellites and SNP panels for genetic identification, traceability and assessment of parentage in an inbred Angus herd. Genetics and Molecular Biology 36(2), 185-191.

Granevitze, Z., Hillel, J., Feldman, M., Six, A., Eding, H., Weigend, S. (2009) Genetic structure of a wide-spectrum chicken gene pool. Animal Genetics 40(5), 686-693.

Hanusová, E., Oravcová, M., Hanus, A., Hrnčár, C., (2017) Factors Affecting Growth in Native Oravka Chicken Breed. Slovak Journal of Animal Science 2017(3), 112117.

Heaton, M.P., Harhay, G.P., Bennett, G.L., Stone, R.T., Grosse, W.M., Casas, E., Keele, J.W., Smith, T.P., Chitko-McKown, C.G., Laegreid, W.W. (2002) Selection and use of SNP markers for animal identification and paternity analysis in U.S. beef cattle. Mammalian Genome 13, 272-281. 
Hillel, J., Groenen, M.A.M., Tixier-Boichard, M., Korol, A.B., David, L., Kirzhner, V.M., Burke, T., Barre-Dirie, A., Crooijmans, R.P.M.A., Elo, K., Feldman, M.W., Freidlin, P.J., Mäki-Tanila, A., Oortwijn, M., Thomson, P., Vignal, A., Wimmers, K., Weigend, S.(2003) Biodiversity of 52 chicken populations assessed by microsatellite typing of DNA pools. Genetics Selection Evolution 35(5), 533557.

Chmelničná, L. (2004) Oravka. In 'Ohrozené plemená zvierat na Slovensku' (Kadlečík O, et al.) pp. 37-52. (Nitra: SPU)

Jobling, M.A., Gill, P. (2004) Encoded evidence: DNA in forensic analysis. Nature Reviews Genetics 5(10), 739-751

Jorde, L.B., Watkins, W.S., Bamshad, M.J., Dixon, M.E. (2000) The distribution of human genetic diversity: A comparison of mitochondrial, autosomal, and Ychromosome data. American Journal of Human Genetics 66, 979-988

Krawczak, M. (1999) Informativity assessment for biallelic single nucleotide polymorphisms. Electrophoresis 20, 16761681.

Moioli, B., Georgoudis, A., Napolitano, F., Catillo, G., Giubilei, E., Ligda, Ch., Hassananec, M. (2001) Genetic diversity between Italian, Greek and Egyptian buffalo populations. Livestock Production Science 70(3), 203-211.

Olowofeso, O., Wheto, M., Durosaro, S.O., Bankole, K.O., Adepoju, D.A., Folarin, O.V. (2016) Combined Exclusion Probabilities of Ten Microsatellite Markers used with Nigerian Chicken Populations. European International Journal of Science and Technology 5(4), 21-32.

Orrú, L., Napolitano, F., Catillo, G., Moioli, B. (2006) Meat molecular traceability: How to choose the best set of microsatellites? Meat Science 72, 312-317.

Pariset, L., Savarese, M.C., Cappuccio, I., Valentini, A. (2003) Use of microsatellites for genetic variation and inbreeding analysis in Sarda sheep flocks of central Italy.
Journal of Animal Breeding and Genetics 120(6), 425-432.

Rosa, A.J.M., Sardina, M.T., Mastrangeloa, S., Tolone, M., Portolanoa, B. (2013) Parentage verification of Valle del Belice dairy sheep using multiplex microsatellite panel. Small Ruminant Research. Elsevier B.V. 113(1), 62-65.

Rosenbom, S., Costa, S.V., Al-Araimi, N., Kefena, E., Abdel-Moneim, A.S., Abdalla, M.A., Bakhiet, A., Beja-Pereira, A. (2015) Genetic diversity of donkey populations from the putative centers of domestication. Animal Genetics 46(1), 30-36.

Saitou, N., Nei, M. (1987) The Neighbor-joining Method: A New Method for Reconstructing Phylogenetic Trees Molecular Biology and Evolution 4(4), 406-425.

Sardina, M.T., Tortorici, L., Mastrangelo, S., Di Gerlando, R., Tolone, M., Portolano, B. (2015) Application of microsatellite markers as potential tools for traceability of Girgentana goat breed dairy products. Food Research International 74, 115-122

Seo, D.W., Hoque, M.R., Choi, N.R., Sultana, H., Park, H.B., Heo, K.N., Kang, B.S., Lim, H.T., Lee, S.H., Jo, C., Lee, J.H. (2013) Discrimination of Korean native chicken lines using fifteen selected microsatellite markers. AsianAustralasian Journal of Animal Sciences, 26(3), 316-322.

Simianer, H. (2005) Decision making in livestock conservation. Ecological Economics 53(4), 559-572.

Sokołowicz, Z., Krawczyk, J., Świątkiewicz, S. (2016) Quality of Poultry Meat from Native Chicken Breeds - A Review. Annals of Animal Science 16(2), 347-368.

Stanford, K., Mcallister, T.A. (2001) Traceability in cattle and small ruminants in Canada. OIE Revue Scientifique et Technique 20(2), 510-522.

Tadano, R., Nagasaka, N., Goto, N., Rikimaru, K., Tsudzuki, M. (2013) Genetic characterization and conservation priorities of chicken lines. Poultry Science 92(11), 2860-2865 
Tolone, M., Mastrangeloa, S., Rosa, A.J.M., Portolanoa, B. (2012) Genetic diversity and population structure of Sicilian sheep breeds using microsatellite markers. Small Ruminant Research. Elsevier B.V, 102(1), $18-25$.

Witzenberger, K.A., Hochkirch, A. (2011) Ex situ conservation genetics: A review of molecular studies on the genetic consequences of captive breeding programmes for endangered animal species. Biodiversity and Conservation 20(9), 18431861.

Yilmaz, O., Sezenler, T., Sevim, S., Cemal, I., Karaca, O., Yaman, Y., Karagan, O. (2015) Genetic relationships among four Turkish sheep breeds using microsatellites. Turkish Journal of Veterinary and Animal Sciences 39(5), 576-582.

Zhou, Y., Liu, Y-P., Kang, L., Meng, X-J., Li, L., Zhu, Q. (2008) Correlation between microsatellite loci and onset of lay and egg quality traits in Chinese Silkies, Gallus gallus. Journal of Poultry Science 45(4), 241-248.

\section{Acknowledgment}

This work was supported by the Slovak Research and Development Agency under the contract no. APVV-17-0508 and grant KEGA 025SPU-4/2019. 